\title{
Reducing Broadcasting Route Request Packet through LF-AODC
}

\author{
Mengurangkan Paket Permintaan Penyiaran Halaan melalui LF-AODC
}

\author{
Roswan Ismail ${ }^{1}$, Che Zalina Zulkifli ${ }^{2}$, Khairulanuar Samsudin ${ }^{2}$ \\ ${ }^{I}$ Faculty of Arts, Computing, and Creative Industry, Universiti Pendidikan Sultan Idris; iewanis@ gmail.com \\ ${ }^{2}$ Faculty of Arts, Computing, and Creative Industry, Universiti Pendidikan Sultan Idris; \{chezalina, \\ khairul\}@fskik.upsi.edu.my
}

\begin{abstract}
Ad hoc on-demand distance vector (AODV) is one of the commonly used reactive routing protocols in mobile ad hoc network (MANET) as it can achieve relatively better communication performance. However, AODV can lead to heavy routing overhead and additional delay due to the flooding broadcast of route request (RREQ) packets during the route discovery cycle. Additionally, the multiple route reply (RREP) packets in response to a single RREQ can also contribute to overhead and additional delay. Thus, a new algorithm called Less Flooding-AODV (LF-AODV) was proposed to reduce the broadcasted RREQ and the transmitted RREP during the route discovery cycle by decreasing the number of nodes involved in the route establishment phase. A simulation test was carried out to compare the difference in performance between LF-AODV and AODV algorithms. The simulation test revealed that the steps of the route discovery process in LF-AODV were significantly reduced, thus improving its performance in terms of packet delivery fraction, end-toend delay and routing overhead compared to the traditional algorithm. Clearly, these results reinforce the theoretical principles used in formulating the new algorithm of LF-AODV.
\end{abstract}

Keywords: Wireless Ad-Hoc Network, Mobile Ad-hoc Network, Routing Protocol, AODV.

\begin{abstract}
Abstrak
Vektor ad hoc jarak jauh on-demand (AODV) adalah salah satu protokol penghalaan yang sering digunakan dalam rangkaian ad hoc mudah alih (MANET) kerana ia dapat mencapai prestasi komunikasi yang lebih baik. Bagaimanapun, AODV boleh menyebabkan halaan beban pengeluaran yang berat dan kelewatan tambahan disebabkan oleh kebanjiran paket permintaan penyiaran halaan (RREQ) semasa kitaran penemuan halaan. Selain itu, paket kepelbagaian maklum balas halaan (RREP) sebagai maklum balas kepada RREQ tunggal turut menyumbang kepada beban pengeluaran dan kelewatan tambahan. Oleh itu, satu algoritma dikenali sebagai AODV-Kurang Kebanjiran (LFAODV) dicadangkan untuk mengurangkan penyiaran RREQ dan penghantaran RREP semasa kitaran penemuan halaan dengan mengurangkan bilangan nod yang terlibat dalam fasa penubuhan halaan. Satu ujian simulasi telah dijalankan untuk membandingkan prestasi antara algoritma LFAODV dengan AODV. Ujian simulasi ini mendedahkan bahawa langkah proses penemuan halaan dalam LF-AODV telah dikurangkan dengan agar ketara, dengan itu ia telah meningkatkan prestasi
\end{abstract}


dari segi pecahan penghantaran paket, kelewatan akhir dan penghalaan beban pengeluaran berbanding dengan algoritma tradisional. Jelas sekali, keputusan ini menguatkan prinsip teori yang digunakan dalam merumuskan LF-AODV sebagai algoritma baharu.

Kata kunci: Rangkaian ad-hoc tanpa wayar, rangkaian ad-hoc mudah alih, protokol penghalaan, AODV.

\section{INTRODUCTION}

Mobile Ad hoc Network (MANET) is a combination of two or more mobile nodes that communicate to each other through wireless links, without any support of fixed infrastructure or centralized administration (Quispe \& Galan, 2014; Layuan et. al., 2007; Li \& Xiao, 2005; Mani et. al., 2013; Mohseni et. al., 2010; Jayakumar \& Gopinath, 2007; Manickam et. al., 2011; Boukerche, 2002). These mobile nodes, which are free to move in any directions, rely on batteries to operate may connect to or leave a network at any time without restriction. This self-organized and self-configured MANET comprises multiple nodes such as laptops, personal digital assistants (PDAs), smart phones, MP3 players, and digital cameras whereas this network can be set up anytime and anywhere, is an appropriate network for emergencies in which existing infrastructures are inadequate or infeasible to be deployed in disastrous areas, or existing infrastructures may be totally damaged, causing a serious communication breakdown.

In MANET in order to establish and maintain valid routes to allow communicating nodes to transmit and deliver the packets among them routing protocol is the key focuses. In essence, the routing protocols assist nodes or devices to choose in which way to route packets in a network. The process of route packets from a source node to a destination node involves two steps: route selection for the source node and packet delivery to the correct destination node. Thus, the routing protocols designed for MANET should be able to cope with the nature of MANET that is highly mobile and the topologies of which can change rapidly. Generally, the routing protocols used in the network can be classified into two classifications: proactive (table-driven), and reactive (on-demand) routing protocols depends on whether the routes are continuously updated or react to demand (Jayakumar \& Gopinath, 2007; Boukerche, 2002; Kioumoutzis et. al., 2012; Prakash et. al., 2010; Kulkarni et. al., 2009; Nissar et. al., 2015; Qabajeh et. al., 2015; Bourkeche et. al., 2011; Bourkeche, 2004; Pandey et. al., 2005; Kuppusamy et. al., 2011).

Proactive protocols such as optimized link state routing (OLSR) and destination-sequenced distance vector (DSDV) maintain the network topology information by broadcasting periodic routing updates through the network within the routing tables (Nissar et. al., 2015). Each node maintains its routing tables, which are constantly updated with routing information of every node in the network. These routing protocol use link-state routing algorithms, which frequently flood the link information of a node with its neighbors. In contrast, reactive protocols such as ad hoc on-demand (AODV) and dynamic source routing (DSR) maintain the routes to the destinations only when they are required (Nissar et. al., 2015). Thus, each node in the network discovers or maintains a route between a source and a destination based on demand. These protocols flood a control message during the process of 
discovering a route. Therefore, after the route is discovered, a bandwidth is used for data transmission.

Both, proactive and reactive protocols offer different advantages and disadvantages based on their characteristics. The main advantage of proactive protocols is that it always updates the routing information, thus it produces a slight delay in discovering a route from a source node to a destination node. However, it produces high message overheads and uses a large amount of resources, such as power and bandwidth. Whereas, the main advantage of reactive protocols is that they need less routing information (Nissar et. al., 2015). Therefore, these protocols reduce the routing load and messaging overhead, and they use lesser resources compared to proactive. Nevertheless, the reactive protocols produce an additional delay in discovering a new route.

In this paper, AODV, being one of the most commonly used reactive routing protocols, was selected as a focal point of discussion. It has become one of the promising protocols for MANET due to its relatively higher communication performance as it has been designed as an improvement over the DSDV and DSR protocols (Geetha \& Sankar, 2012; Rekha \& Ashoka, 2014).

\section{LITERATURE REVIEW}

\section{AODV Routing Protocol}

The Ad Hoc On-demand Distance Vector (AODV) (Makkar et. al., 2011; Li et. al., 2012; Rasheed \& Mohammad, 2009; Yassein et. al., 2006; Jasani, 2012; Khan \& Vishwakarma, 2014; Lakkakorpi et. al., 2010) is an on-demand routing protocol that utilizes routing tables to store routing information. These routing tables hold information such as destination address, next hop address, hop count, destination sequence number, and life time (expiration time). AODV requires conserving the routing information of the active paths in reactive protocol. Whenever a source node desires to send packets to a destination node; it starts a route discovery operation in order to discover a route to the destination if there is no such route is available in its routing table. During the route discovery process, the source node broadcasts route request (RREQ) packets to the neighboring nodes, which comprises of the addresses and the sequence number of the source and destination nodes, the broadcast ID, and the hop count. The source and destination address, together with the broadcast ID, uniquely identifies the route request packet sent, the sequence number ensures a loop-free and up-todate route in AODV, and the hop-count maintains the number of nodes between the source and destination.

When the RREQ packets arrive at recipient nodes, each recipient node checks if it already received a RREQ with the similar broadcast ID and source address. If such information is available, then it drops redundant RREQ messages. If the receiving node has not received this RREQ before, and it is not the destination node nor it has a route to a destination node, it increments the hops count by one and rebroadcasts that RREQ to other neighboring nodes in the similar method. However, if the 
receiving node is a destination node or it is a node that has a route to the destination, it checks the destination sequence numbers of received RREQ packet with destination sequence number it currently has. Subsequently, the RREQ packets with lower destination sequence numbers will be dropped. Then, it generates a Route Reply (RREP) and unicasts it in a hop-by-hop fashion to the source node.

The source records the route to the destination and begins to send data along the route from which the RREP arrived after it receives the RREP. The route with the shortest hops count is chosen if multiple RREPs are received by the source. The node will broadcast a route error (RRER) packet to the source node if a link break happens. A route discovery operation re-initiate by the affected source to find another route to the preferred destination. In this case, intermediate node receives the RREQ packet then creates entries in their routing tables to the source. Likewise, nodes that receive the RREP packet create entries for the destination node. Thus, the routing table entry comprises the next hop to the corresponding node. Figure 1 illustrates the basic operation flow of AODV routing protocol. In addition, Figure 2 and 3 shows the basic AODV message functioning and the routing information contained in the routing table of AODV nodes, respectively.

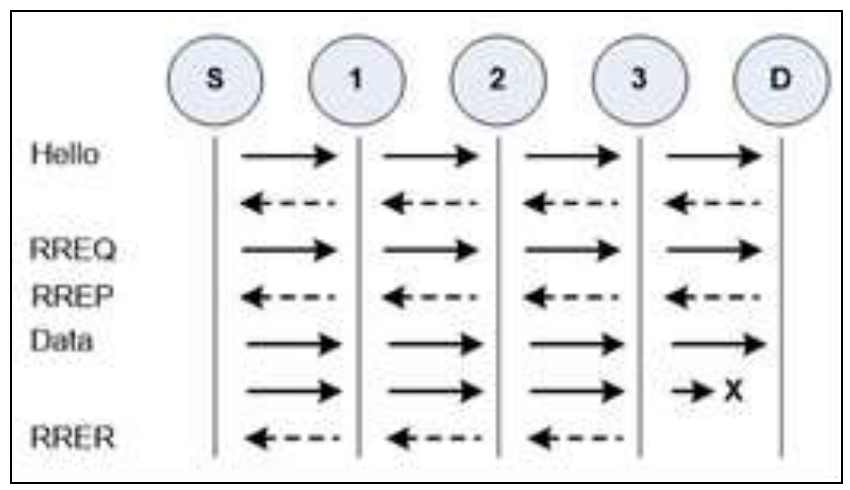

Figure 1: Basic AODV message functioning.

\begin{tabular}{|l|l|l|l|l|} 
Dest. & Seq. No. & Hop Count & Next Hop & Expiration Time \\
\hline
\end{tabular}

Figure 2: Routing table entries of AODV nodes. 


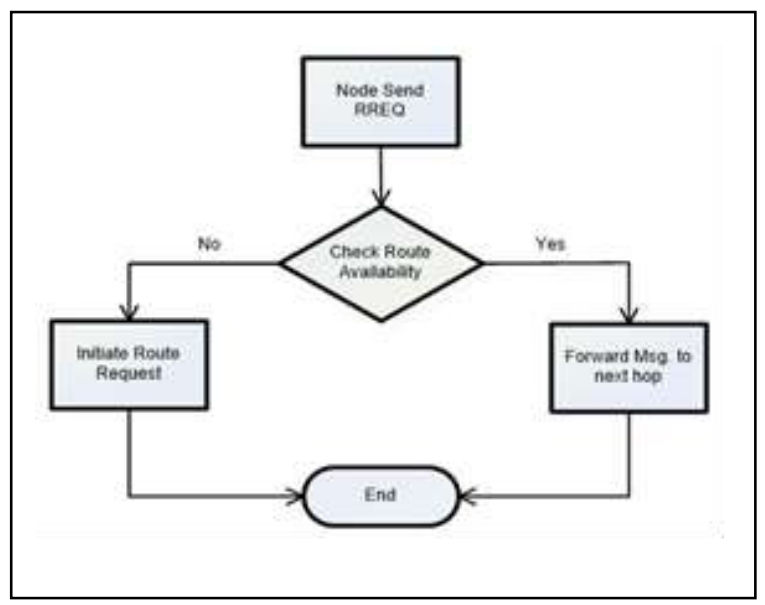

Figure 3: Basic operation flow of AODV (Rasheed \& Mohammad, 2009).

One of the disadvantages of AODV is the RREQ packet that has been broadcasted to the entire nodes in the network during the route establishment process can lead to a heavy control overhead. Moreover, AODV constructs the route using hop-by-hop or single hop technique, thus taking some time to complete the route discovery process to a single RREQ packet. Another disadvantage of AODV is that multiple route reply packets (RREP) in response to a single route request (RREQ) packet can lead to unnecessary resource consumption and contribute to an additional overhead and delay due to route reply message loss (Zarei, 2009; Zarei et. al., 2008). Thus, it is important to enhance the AODV routing protocol to reduce overhead during the route establishment process, which can affect the routing performance such as end-to-end delay and packet delivery ratio (PDR), especially in large and dense networks.

\section{AODV Improvement}

Many studies focusing on the improvement of AODV have been carried out to solve the routing overhead issue during the route discovery cycle. For example, Kim et al. (Kim et. al., 2006) proposed the reverse AODV (R-AODV) to overcome the effect due to loss of the single unicasted route reply (RREP) message along the reverse path during the route discovery process (Das, 2013). With RAODV, the RREP message is not unicast as the destination node uses reverse RREQ to find the source node. In this case, the broadcast procedure is the same as the RREQ in AODV where the RREQ packet is broadcasted all over the network until it reaches the destination node. Nevertheless, when nodes receive the RREQ message, they generate R-RREQ message and broadcast it to neighbor nodes within the transmission range, just like what the RREQ of source node does (Kim et. al., 2006). The source node will start to deliver data packets by using the first received R-RREQ packet while the late arrived packets are stored for future used (Das, 2013). If a link break occurs, the 
generation of RERR packet is carried out in the same method as AODV. Effectively, the R-AODV reduces path fail correction messages and achieves better performance in terms of end-to-end delay, packet delivery ratio (PDR) and energy consumption during the route discovery process (Kim et. al., 2006; Das, 2013). However, R-AODV produces more control packet overhead than AODV because the former floods route reply message, but such route reply message in the latter is unicast along the reverse path (Kim et. al., 2006).

Several researchers (Zarei et. al., 2008) have optimized AODV by adding link stability parameter to R-AODV, termed as MRAODV, in order to decrease the overhead of discovery routing. In the modified reverse AODV (MRAODV), a source node first broadcasts a RREQ packet when it wants to communicate with a destination node. When the destination node obtains the RREQ message, it broadcasts R-RREQ message to find the source node. In contrast with the R-AODV, every intermediate node that receives R-RREQ message will compute the route stability and record it to the link stability field, which is added to R-RREQ packet.

The source node with received R-REQ has the information of the stability of the available route to the destination node by enabling the source node in selecting a route with the highest stability. As data are transmitted, then the information is applied to the route maintenance. Furthermore, as an intermediate node moves, link breaks will occur that disrupts an active route; thus, a new route must be designated. In this case instead of selecting a failed node preferably to select a stable route of a source node. With MRAODV, packet overhead of AODV and R-AODV can be decreased due to improved success rate of route discovery. However, MRAODV increases the packet size as route stability information has to be added to R-RREQ message.

In Shetty (2013), the author proposed RO-AODV (Route Optimized Ad hoc On-demand Distance Vector) to limit the route request broadcasting activity based on route optimization. It uses accumulation path list to record all path nodes when a node receives a RREQ to update the route table (Padwad \& Sonekar, 2014). With RO-AODV, nodes are allowed to record their identities by adding their addresses as extra routing information in the RREQ packet. In order for the node to have a routing table entry to the rest of the nodes each RREQ packets must contain a source route for the nodes along the path. After each intermediate node adds its address to the RREP packet the RREP message is unicast back to the source node. Hence, the previously visited nodes were stored in the forwarded RREP packet.

Similar to the RREQ, each intermediate node visited by the RREP will update the routing table in addition to the destination node. According to the guidelines of AODV, in the precursor lists entries are created by a node forwarding a route reply back to the source node. Any pending packets are sent to that node if an entry is updated with any intermediate nodes. This technique optimizes AODV to perform efficiently and reduces routing overhead, delay, and energy consumption under high load conditions. This method, however, increases the packet header as it needs to maintain the source route (Padwad \& Sonekar, 2014). 
Several researchers (Geetha \& Umarani, 2011) managed to improve AODV by introducing and applying the MPR (Multi Point Relay) mechanism, which was first introduced in OLSR, to reduce the number of messages broadcasted during the route discovering cycle. The basic principle of this mechanism (MPRAODV) is that the broadcasted RREQ packets are forwarded only by the MPR node, which is computed and assigned with the set number of nodes. There will be several MPR nodes for several sets of nodes. This technique can limit the flow of network as only MPR nodes are allowed to disseminate messages to the network. The simulation results in (Geetha \& Umarani, 2011) show that MPRAODV performs much better than AODV in terms of end-to-end delay, packet delivery ratio, and routing overhead. However, when the network density is increased, MPRAODV performs poorly than AODV due to disconnections and packet loss in dense traffic.

The authors in (Yadav et. al., 2012) proposed an improved AODV (I-AODV) based on probability and node density paths. The objective of the proposed method is to reduce the number of RREQ packets, which would reduce the number of broadcast and collisions in the network. This method allowed the forwarded RREQ packet of each intermediate node to its neighbor based on the compactness of neighborhood nodes. Therefore, the neighborhood compactness is divided into two classifications: dense and sparse. The node retransmits the RREQ packet with high probability while in sparse region so that it can reach the full number of nodes; otherwise, the node forwards the packet with low probability when in the dense network region. In this case, the algorithm prevents inundated flooding of the request packets in the entire network. The performance of the I-AODV in terms of routing overhead, end-to-end delay, the number of broadcast packets and the number of collisions is relatively higher than AODV. However, this technique is based on node density only, leaving out other elements in its design.

Table 1 summarizes the purposes, advantages, and limitations of the various strands of AODV. In contrast with previous works, the present researchers proposed a simpler method named Less Flooding AODV (LF-AODV), the main aim of which was twofold: to reduce the number of RREQ messages broadcasted during the route discovering cycle and to reduce the multiple responses of RREP packets for a single RREQ. These reductions can be realized by decreasing the number of nodes involved in rebroadcasting the control packets during the route discovering cycle. With such method, limitations of AODV as well as R-AODV and MPRAODV can be overcome, as explained in detail, in the following sections.

Table 1: Summary of the improved AODV protocol.

\begin{tabular}{llll}
\hline Protocol & \multicolumn{1}{c}{ Purposes } & Advantages & \multicolumn{1}{c}{ Limitations } \\
\hline R-AODV & $\begin{array}{l}\text { To reduce the loss of route reply } \\
\text { messages during the route discovery } \\
\text { process }\end{array}$ & $\begin{array}{l}\text { Reduces delay, } \\
\text { energy consumption } \\
\text { Improves PDR }\end{array}$ & $\begin{array}{l}\text { R-AODV has more control packet overhead } \\
\text { compared to AODV. }\end{array}$ \\
\hline MRAODV & $\begin{array}{l}\text { To ensure the source node can select a } \\
\text { route with the highest stability to decrease } \\
\text { the overhead of discovery routing }\end{array}$ & Reduces delay & $\begin{array}{l}\text { MRAODV increases the packet size as route } \\
\text { stability information needs to be added to R- } \\
\text { RREQ message }\end{array}$
\end{tabular}




\begin{tabular}{clcl}
\hline Protocol & \multicolumn{1}{c}{ Purposes } & Advantages & \multicolumn{1}{c}{ Limitations } \\
\hline RO-AODV & $\begin{array}{l}\text { To limit the route request broadcasting } \\
\text { activity using cache mechanism }\end{array}$ & $\begin{array}{l}\text { Reduces delay, } \\
\text { routing load } \\
\text { Improves PDR }\end{array}$ & $\begin{array}{l}\text { RO-AODV only improves the performance of } \\
\text { AODV under conditions of high load, and } \\
\text { moderate to high mobility. }\end{array}$ \\
\hline MPRAODV & $\begin{array}{l}\text { To introduce the MPR technique to AODV } \\
\text { such as to reduce the number of } \\
\text { broadcasted messages during the route } \\
\text { discovery phase }\end{array}$ & $\begin{array}{c}\text { Reduces delay, } \\
\text { routing overhead }\end{array}$ & $\begin{array}{l}\text { MPRAODV performs poorly than AODV due } \\
\text { to disconnections and packet loss in dense } \\
\text { traffic }\end{array}$ \\
\hline I-AODV & $\begin{array}{l}\text { To replace a blind flooding technique with } \\
\text { the selective flooding technique, which is } \\
\text { done based on neighbouring node } \\
\text { compactness and probability of RREQ } \\
\text { rebroadcasting to reduce the routing } \\
\text { overhead. }\end{array}$ & $\begin{array}{l}\text { Reduces delay, } \\
\text { routing overhead, } \\
\text { control overhead }\end{array}$ & $\begin{array}{l}\text { I-AODV reduces the number of rebroadcast } \\
\text { messages. However, this technique is based on } \\
\text { node density only, leaving out other elements. }\end{array}$ \\
& $\begin{array}{c}\text { Improves Throughput, } \\
\text { PDR }\end{array}$ & \\
\hline
\end{tabular}

Note . For advantages, PDR $=$ Packet Delivery Ratio, delay $=$ end-to-end delay.

\section{METHOD AND DESIGN}

\section{Performance Evaluation Methodology}

The theoretical principles used in conceptualizing the algorithm of LF-AODV were examined in a simulation test using NS-2 (v-2.3.3), whereas it is one of the widely recognized simulators for networking research. The simulations were run for 50 nodes that were randomly placed in a region of 1000 by 1000 meters using the random way point (RWP) mobility model. The traffic type was set to the constant bit rate (CBR) traffic with 512-byte data packets by varying the number of CBR connections for the observations. The packet-sending rate is set to four (4) packets per second and the transmission distance of each node was set to 250 meters. Table 2 summarizes the details of simulation parameters.

Table 2: Simulation settings.

\begin{tabular}{cc}
\hline Parameters & Values \\
\hline Protocols & AODV, LF-AODV \\
Number of nodes & 50 \\
Network Size & $1000 \mathrm{~m} * 1000 \mathrm{~m}$ \\
Mobility Model & Random Way Point (RWP) \\
Traffic Type & Constant Bit Rate $(\mathrm{CBR})$ \\
Pause time $(\mathrm{s})$ & 30 \\
Number of connections & $10,20,30,40,50$ \\
Data rate & 4 packets/s \\
Packet Size & $512 \mathrm{bytes}$ \\
Maximum Speed & $20 \mathrm{~m} / \mathrm{s}$ \\
Transmission range & $250 \mathrm{~m}$ \\
\hline
\end{tabular}


The following metrics were used to evaluate the performance of AODV and LF-AODV protocols:

\section{Packet Delivery Fraction (PDF)}

Packet Delivery Fraction is defined as the ratio of the number of packets received by the destination node to the total number of packets sent by the source node (Kang et. al., 2010). This ratio is expressed as follows:

$$
P=P_{r} / P_{s}
$$

where ${ }^{P}$ is the packet delivery ratio, $P_{r}$ is the total number of packet received, and $P_{s}$ is the total number of packet sent.

\section{Average End-to-End Delay}

Average end-to-end Delay refers to the time taken for a packet to arrive at the destination from the source (Kang et. al., 2010), which is expressed as follows:

$$
A E=\left(P_{s t}-P_{r t}\right) / P_{r}
$$

where $A E$ is the average end-to-end delay, $P_{s t}$ is the packet sending time and $P_{r t}$ is the packet received time.

\section{Routing Overhead}

Routing Overhead (RO) is defined as the total number of control messages (route request messages, route reply messages and route error messages) transmitted by the source node to the destination node during route discoveries (Kang et. al., 2010). The formula for RO is as follows:

$$
R O=\left(R_{r e q}+R_{r e p}+R_{\text {err }}\right)
$$

where $R O$, is the routing overhead, $R_{r e q}$ is the total number of route request messages, $R_{r e p}$ is the total number of route reply message, and $R_{e r r}$ is the total number of route error messages. 


\section{Proposed Design of LF-AODV}

Existing AODV is a reactive protocol, which determines the route to a destination only when it is required. It defines the route using flooding broadcast techniques, in which a node floods the network with a route request (RREQ) message and waits for the route reply (RREP) message to establish a route to the destination node. This technique does not require constant broadcast messages, so it reduces the routing load when compared to proactive protocol. However, the routing overhead in reactive AODV protocol remains as a contentious issue among practitioners, entailing more efforts to address it by drastically reducing such overheard during the route establishment process. In particular, the imperative to further improve existing AODV is all the more important in large and dense networks in which communication traffic is intense.

Theoretically, the broadcast floods can be reduced by reducing the number of nodes that take part in rebroadcasting a route request (RREQ) message during a route discovery cycle. The reduction in broadcast floods can be realized when the route request message (RREQ) is only broadcasted to certain nodes rather than to the entire nodes in a network. With the traditional flooding technique, the entire nodes will retransmit all packets; but with LF-AODV, only two-hop neighbour nodes will retransmit packets, thus reducing the number of transmissions needed to deliver the packets successfully. Subsequently, these two-hop neighbour nodes will reach all intermediate two-hop neighbours until the destination node is found.

In essence, the proposed LF-AODV includes the same two routing phases of AODV, namely route discovery and route maintenance. In addition, the former's basic operation flow is also similar to the latter's, such that when the source node wants to send data to a destination node, it sends the RREQ packet to neighbouring nodes and checks the route availability first. If the route is not available, the source node then initiates a RREQ packet. If the route to the destination node is available, then the RREQ packet will be forwarded to other nodes until the destination node is found. However, with LF-AODV, the packets will be forwarded only to the neighbour nodes with two-hops, and not to the entire nodes as normally encountered in AODV. In this case, the entire one-hop neighbours of source node do not take part in the process of retransmitting the packets - thus lies the difference between AODV and LF-AODV.

As LF-AODV applies the technique of two-hop neighbour, its routing table must hold additional routing information, namely the addresses of two-hop neighbour nodes, which is updated in the table using the Hello message. Figure 4 shows the format of routing table entries for LF-AODV nodes. Similar to RREQ packets, the multiple response of the RREP message to a single RREQ message will be forwarded only by the next two-hop neighbour nodes too. Therefore, this technique can reduce both the transmission number of RREQ and RREP packets in the route discovery cycle.

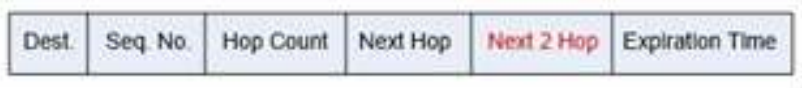

Figure 4: Routing table entries of the proposed LF-AODV. 
The differences between the traditional AODV and LF-AODV are as follows:

\section{Using the traditional AODV}

- A source node "S" broadcasts a message " $\mathrm{M}$ "

- Each node "N" that receives the message will forward M, unless this message has been previously forwarded.

Using LF-AODV

- A source node " $\mathrm{S}$ " broadcasts its message " $\mathrm{M}$ " to two-hop neighbor nodes " $\mathrm{Cn}$ ".

- $\mathrm{Cn}$ that receives $\mathrm{M}$ will rebroadcast this message to other node Cn only if:

a) $\mathrm{Cn}$ is the next two-hop neighbor of the previous $\mathrm{Cn}$;

b) $\mathrm{Cn}$ is the last neighbor node of the previous $\mathrm{Cn}$.

Establishing LF-AODV involves making three changes to the traditional AODV routing protocol as follows:

\section{Hello-Message Function}

A node uses Hello message to define its one-hop and two-hop neighbours, and regroups them in a routing table. In this part of the protocol, a small program to regroup the information of one-hop and two-hop neighbours in a table and programs to select the listed two-hop neighbour nodes for broadcasting the packet are introduced. Each time a new node is added to the network, the table of one-hop and two-hop neighbour's information is updated accordingly.

\section{Send Request Function}

- Select the next two-hop neighbor nodes in the network.

- Broadcast RREQ message to the next two-hop neighbor node of previous two-hop neighbor node.

\section{Forwarding Request Function}

In this part of the protocol, small changes were made by adding a simple condition in the block transmission request. When a node receives a route request (RREQ) packet, the node checks if it is the destination node or not. If the node is not the destination node, and there is no route or no twohop neighbor node to rebroadcast the packet, the node will drop the packet. However, if the node has next two-hop neighbor node, the node will rebroadcast the packet to the next two-hop neighbor node. The following block refers to the forwarding mechanism applied in the LF-AODV. 


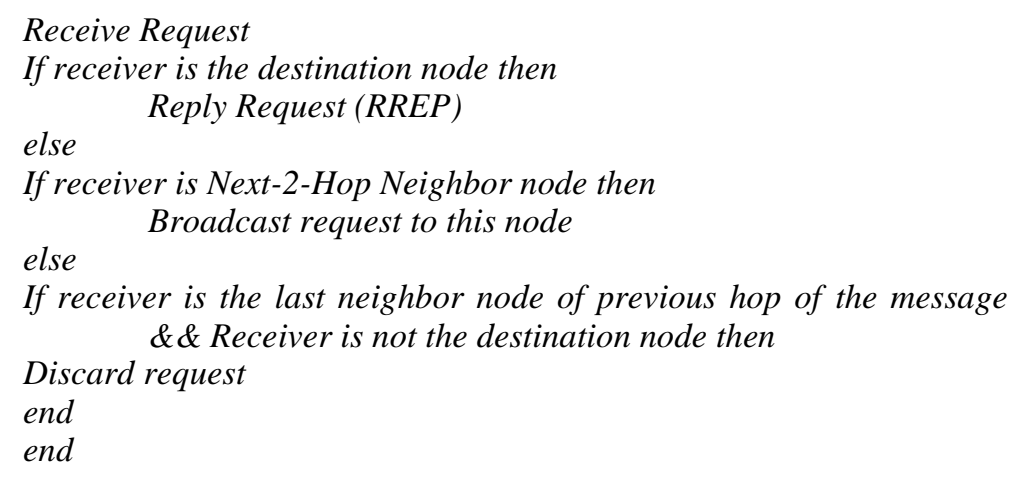

Figure 5: LF-AODV's forwarding mechanism block.

\section{RESULTS AND DISCUSSIONS}

\section{Comparative Analysis of AODV and LF-AODV}

The comparative analysis of AODV and LF-AODV was based on the route discovery algorithms operating in a network. Figure 6 and Figure 7 show the steps in the route discovery process of AODV and LF-AODV algorithms, respectively. Consider a network containing seven nodes, namely S, A, B, C, D, E, and F. When node S (the source node) wants to send data to node F (the destination node), it checks the route availability to node $\mathrm{F}$ in its routing table. If it has no route to node $\mathrm{F}$ in its routing table, node $S$ creates a route request (RREQ) packets and broadcasts it to the all nodes in the network using the single hop technique. When nodes A and B receive the RREQ packets, they update their routing tables for the reverse route to node $S$ and then forward the request packets to nodes $\mathrm{C}$ and $\mathrm{D}$ as nodes $\mathrm{A}$ and $\mathrm{B}$ have no direct routes to node $\mathrm{F}$. When nodes $\mathrm{C}$ and $\mathrm{D}$ receive the RREQ packet, they repeat the same process as carried out by nodes $A$ and $B$, updating their routing tables and then forwarding the RREQ packet to their neighbor nodes. This process continues until the route to the destination node is established. When node F receives the RREQ from node $\mathrm{D}$, the former creates a route reply (RREP) packet and unicasts it to the latter. Subsequently, node D makes a forward route entry to node $F$ and unicasts the RREP to node $A$. The process continues until node $S$ receives the RREP to start sending the data. In this case, the route discovery process with AODV is completed with the steps as highlighted in Figure 6. If the link between node D and node F is broken, node D unicasts a route reply error (RRER) packet to node A that re-unicasts the RRER to node S, informing the link failure.

In essence, the LF-AODV algorithm operates in the same manner as the AODV algorithm except the former broadcasts the packet using a two-hop technique. With LF-AODV algorithm, when node S wants to send data to node $\mathrm{F}$ and it has no available route to $\mathrm{F}$, the former creates a RREQ packet and broadcasts it directly to nodes $\mathrm{C}$ and D. In this case, the broadcast step to nodes A and B is skipped. 


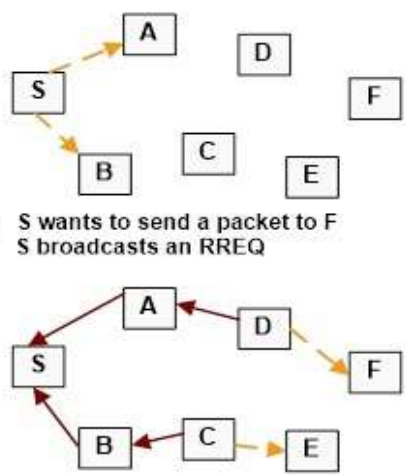

3) C and D establish Reverse Route $C$ and $D$ rebroadcast $R R E Q$

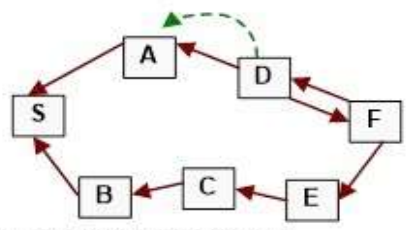

5) F establish Reverse Route F drops duplicate RREQ

D establishes Route

$D$ reunicasts RREP

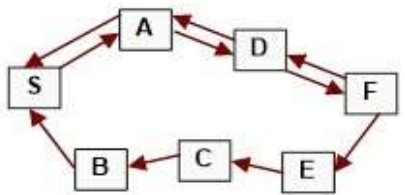

7) S establish Route
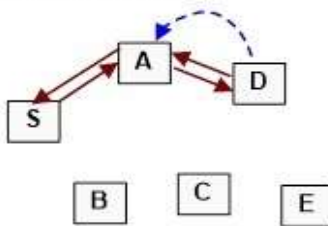

9) Link between $D$ and $F$ broken D unicasts RRER

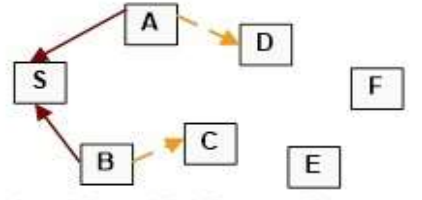

2) $A$ and $B$ establish Reverse Route

$A$ and $B$ rebroadcast RREQ

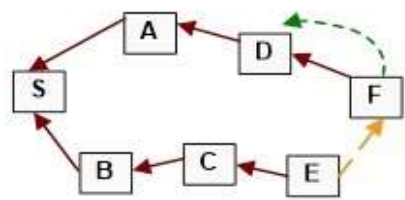

4) E and F establish Reverse Route

E rebroadcast RREQ

$F$ unicasts RREP

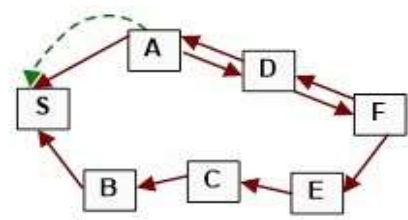

6) A establish Route

$A$ reunicasts RREP

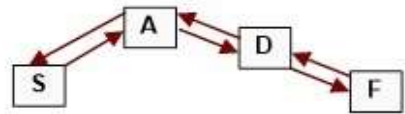

\section{$B \quad C \quad E$}

8) Unused Reverse routes expire
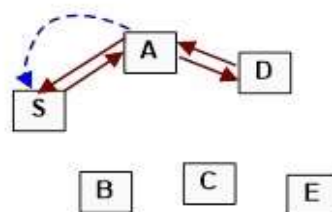

10) A reunicasts RRER

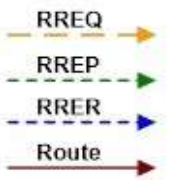

Figure 6: Routing table entries of the proposed LF-AODV 
Then, when nodes $\mathrm{C}$ and $\mathrm{D}$ receive the RREQ packet, they update their routing tables for the reverse route to node $S$ that subsequently forward the RREQ packet to its next two-hop neighbor. In contrast to node $\mathrm{C}$, node $\mathrm{D}$ that has no next two-hop neighbor will forward the RREQ to its one-hop neighbor. Its routing table is update for the reverse route to node $\mathrm{D}$ and drops duplicated RREQ from node $\mathrm{C}$ when node $\mathrm{F}$ receives the RREQ. Then, node $\mathrm{D}$ establishes a route entry to node $\mathrm{F}$ and unicasts the RREP to node $\mathrm{S}$, which can then start sending the data to node $\mathrm{F}$.

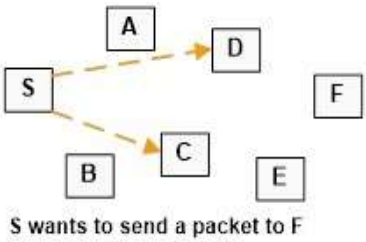

1) $S$ wants to send a packet to $F$ $S$ broadcasts an RREQ

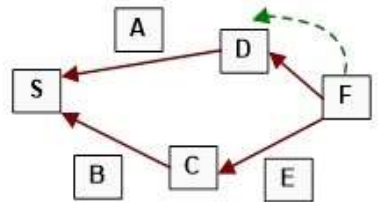

3) F establish Reverse Route F unicasts RREP

F drops duplicate RREQ

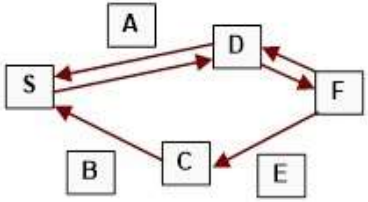

5) S establishes Route

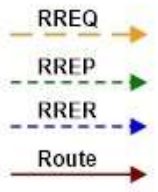

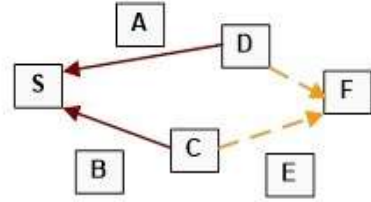

2) C and D establish Reverse Route $C$ and $D$ rebroadcast $R R E Q$

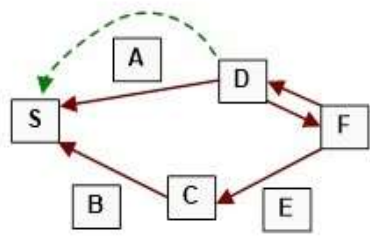

4) D establish Route $D$ reunicasts RREP

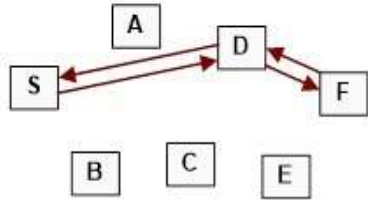

6) Unused Reverse routes expire

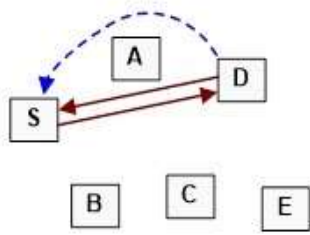

7) Link between $D$ and $F$ broken D unicasts RRER

Figure 7: Routing table entries of the improved algorithm of LF-AODV. 
Clearly, the improved algorithm of LF-AODV, which is based on the two-hop technique, will be able to reduce the number of steps of the route establishment process. Particularly, the reduction in such steps is attributed to a relatively smaller number of nodes participating in route establishment. By reducing the number of participating nodes, the number of broadcasted RREQ message and the transmission of RREP message are substantially reduced. Furthermore, the reduction of participating nodes will be more significant for high-density networks. Therefore, two-hop neighbor technique will be able to reduce routing overhead during the route discovery cycle as well as to reduce the delay in establishing the route.

\section{Simulation Results}

Figure 8 shows simulation results of the packet delivery Fraction (PDF) against the number of CBR connections for LF-AODV and AODV. Evidently, higher number of connections resulted in degradation of PDF, but the degradations of both protocols were markedly different. Clearly, the degradation of LF-AODV was less severe than that of AODV, attesting that the former was more efficient than the latter. Hence, the LF-AODV protocol is able to deal with broken links and packet loss as the number of routing control packets can be reduced during the route discovery process.

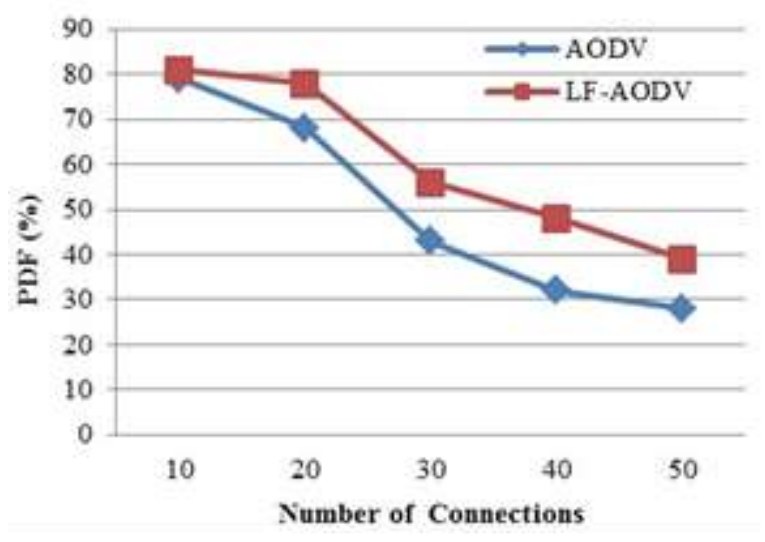

Figure 8: Packet delivery fraction vs number of connections.

Figure 9 shows that the average end-to-end delays of both protocols, which were almost the same at low traffics (i.e., at 10 connections and below). However, the differences in the delays were visibly substantial for higher number of connections, with LF-AODV having lower delays than AODV. Arguably, lower delay of LF-AODV is attributed to the use of fewer devices, thus freeing the wireless channel from massive communication traffic. As a result, the routing discovery can be quickly completed with LF-AODV. On the contrary, long delays produced by AODV are due to the overloading of the network, which include the processing time and queuing time. 


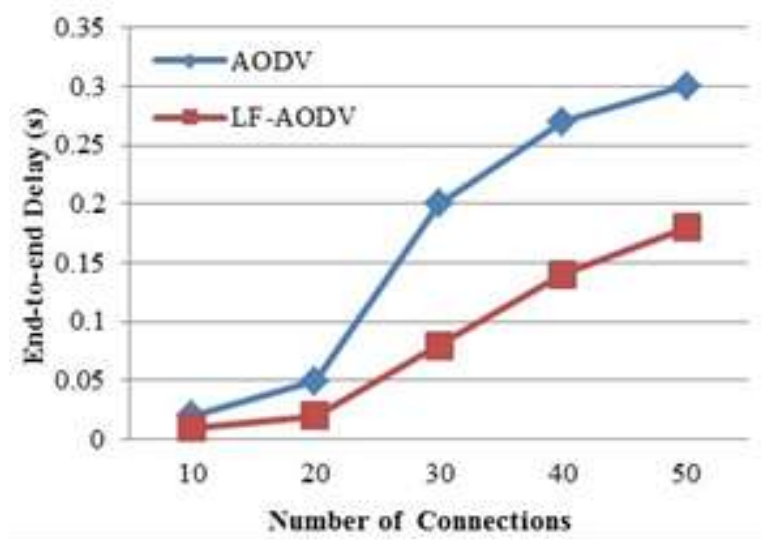

Figure 9: End-to-end delay vs number of connections.

Figure 10 shows the routing overheads of both protocols with varying numbers of CBR connections. It is clear that the routing overheads of LF-AODV were less than that of AODV, the differences in which ranged from $10 \%$ (at low number of connections) to $40 \%$ (at high number of connections). Again, lower routing overheads of LF-AODV protocol is the result of reduced number of routing control packets, RREQ, and RREP during the route discoveries.

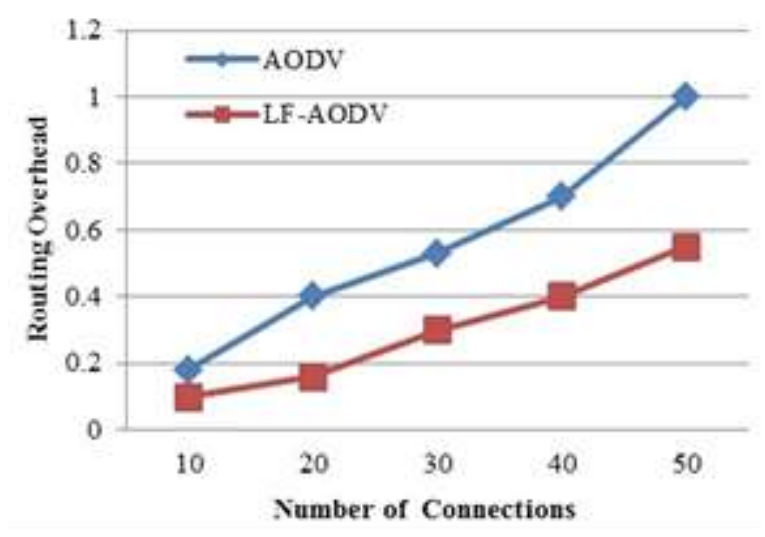

Figure 10: Routing overhead vs number of connections. 


\section{CONCLUSIONS}

This paper highlights the design of the proposed LF-AODV as a practical solution to heavy routing overhead, which is due to massive flooding commonly experienced by the traditional AODV. Particularly, the main aim of LF-AODV is to reduce the broadcasted RREQ and unicast RREP during the route establishment process. With such protocol, the network performance can be further improved by reducing the routing overhead and end-to-end delay during the route discovery cycle. Simulation test performed on LF-AODV and AODV algorithms conclusively showed that the steps of the route discovery process of the former were far fewer than the latter. The simulation test results suggest that the LF-AODV protocol has shorter average end-to-end delays, lower routing overheads, and higher packet delivery fraction - parameters that are critical to the performance of a network. Further research is entailed to compare the performance of LF-AODV with other protocols, such as R-AODV and MPRAODV. In addition, such research should also focus on energy consumption by taking into consideration the different number of nodes, different mobility speeds, and varying sizes of network area.

\section{REFERENCES}

Boukerche, A. (2002). Simulation-based performance comparisons of routing protocols for mobile ad hoc networks. Simulation, 78(7), 401-407. Sage.

Boukerche, A. (2004). Performance evaluation of routing protocols for ad hoc wireless networks. Mobile Networks and Applications, 9(4), 333-342. ACM.

Boukerche, A., Turgut, B., Aydin, N., Ahmad, M. Z., Boloni, L., \& Turgut, D. (2011). Routing protocols in ad hoc networks: A survey. Computer Networks, 55(13), 3032-3080. Elsevier.

Das, P. (2013). Comparison of AODV and R-AODV Routing Protocols by varying Network Mobility, Network Area and Network Density. International Journal of Emerging Technology and Advanced Engineering, 3(8), 472-477.

Geetha, M., \& Umarani, R. (2011). An Overview of Multi Point Relay AODV in Mobile Ad hoc Network. International Journal of Technology and Engineering System (IJTES), 2(1), 71-76.

Geetha, N., \& Sankar, A. (2012). Performance analysis of certain topology based routing protocols of mobile ad hoc network. In Proceedings of the 2012 ACM Research in Applied Computation Symposium (pp. 215-220). ACM.

Jasani, H. (2012). Evaluations of AODV and DSR for QoS Requirements. In Proceedings of the 1st Annual conference on Research in information technology (pp. 1-6). ACM.

Jayakumar, G., \& Gopinath, G. (2007). Ad hoc mobile wireless networks routing protocols-a review. Journal of Computer science, $3(8), 574-582$.

Kang, B. S., Kim, H. S., \& Ko, I. Y. (2010). AODV - RIP: improved security in mobile ad hoc networks through route investigation procedure. Concurrency and Computation: Practice and Experience, 22(7), 816-830. Wiley.

Khan, R., \& Vishwakarma, A. (2014). Enhancement of manet routing protocol. In conference on IT in Business, Industry and Government (CSIBIG) (pp. 1-6). IEEE.

Kim, C., Talipov, E., \& Ahn, B. (2006). A Reverse AODV Routing Protocol in Ad Hoc Mobile Networks. In International Conference on Embedded and Ubiquitous Computing (pp. 522-531). Springer.

Kioumourtzis, G., Bouras, C., \& Gkamas, A. (2012). Performance evaluation of ad hoc routing protocols for military communications. International Journal of Network Management, 22(3), 216-234. Wiley.

Kulkarni, N.S., Gupta, I., \& Raman, B. (2009). On Demand Routing Protocols for Mobile Ad Hoc Network: A Review. In Advance Computing Conference (IACC) 2009, IEEE International, (pp. 586-591). IEEE.

Kuppusamy, P., Thirunavukkarasu, K., \& Kalaavathi, B. (2011). A study and comparison of OLSR, AODV and TORA routing protocols in ad hoc networks. In Electronics Computer Technology (ICECT), 3rd IEEE International Conference on (Vol. 5, pp. 143-147). IEEE. 
Lakkakorpi, J., Pitkanen, M., \& Ott, J. (2010). Adaptive routing in mobile opportunistic networks. In Proceedings of the 13th ACM international conference on Modeling, analysis, and simulation of wireless and mobile systems (pp. 101-109). ACM.

Layuan, L., Chunlin, L., \& Peiyan, Y. (2007). Performance evaluation and simulations of routing protocols in ad hoc networks. Computer Communications, 30(8), 1890-1898. Elsevier.

Li, H., Pan, L., \& Fan, R. (2012). Simulation Research on DSDV and AODV Protocol in Tactical Unit Network. In AsiaSim 2012, Shanghai, 27-36. Springer.

Li, J., Pan, Y., \& Xiao, Y. (2005). Performance study of multiple route dynamic source routing protocols for mobile ad hoc networks. Journal of parallel and distributed computing, 65(2), 169-177. Elsevier.

Makkar, A., Bhushan, B., \& Taneja S. (2011). Behavioral Study of MANET Routing Protocols. International Journal of Innovation, Management and Technology, 2(3), 210-216.

Mani, U., Chandrasekaran, R., \& Dhulipala, V. S. (2013). Study and analysis of routing protocols in mobile ad-hoc network. Journal of Computer Science, 9(11), 1519. Citeseer.

Manickam, P., Baskar, T. G., Girija, M., \& Manimegalai, D. D. (2011). Performance comparisons of routing protocols in mobile ad hoc networks. International Journal of Wireless \& Mobile Networks, 3(1), 98-106.

Mohseni, S., Hassan, R., Patel, A., \& Razali, R. (2010). Comparative review study of reactive and proactive routing protocols in MANETs. In 4th IEEE International Conference on Digital ecosystems and technologies, pp. 304-309. IEEE.

Nissar, N., Naja, N., \& Jamali, A. (2015). A review and a new approach to reduce routing overhead in MANETs. Wireless Networks, 21(4), 1119-1139. Springer.

Padwad, H., \& Sonekar, S. V. (2014). An Empirical Approach of Optimizing AODV Routing Protocol for Route Discovery in Mobile Ad-Hoc Network. International Journal of Computer Science and Information Technologies, 5(3), 4259-4264.

Pandey, A. K., \& Fujinoki, H. (2005). Study of MANET routing protocols by GloMoSim simulator. International Journal of Network Management, 15(6), 393-410. Wiley.

Prakash, S., Saini, J. P., \& Gupta, S. C. (2010). A review of Energy Efficient Routing Protocols for Mobile Ad Hoc Wireless Networks. International Journal of Computer Information Systems, 1(4), 36-46.

Qabajeh, M. M., Abdalla, A. H., Khalifa, O. O., \& Qabajeh, L. K. (2015). A Survey on Scalable Multicasting in Mobile Ad Hoc Networks. Wireless Personal Communications, 80(1), 369-393. Springer.

Quispe, L. E., \& Galan, L. M. (2014). Behavior of Ad Hoc routing protocols, analyzed for emergency and rescue scenarios on a real urban area. Expert Systems with Application, 41(5), 2565-2573. Elsevier.

Rasheed, A., \& Mohammad, K. (2009). Exploration and Comparison of Several AODV Implementations: A Survey. Communications of the ACS 2, 1-9.

Rekha, B., \& Ashoka, D. V. (2014). Performance Analysis of AODV and AOMDV Routing Protocols on scalability for MANETs. In Emerging Research in Electronics, Computer Science and Technology (pp. 173-181). Springer.

Shetty, D. (2013). RO-AODV: Route Optimized Ad-Hoc On-Demand Distance Vector Routing Protocol. doi:10.1.1.696.6865.

Yadav, M. K., Khola, R. K., \& Dembla, D. (2012). Modelling, Analysis \& Implementation of Improved AODV Routing Protocol in MANETs. International Journal of Computer Application, 41(21), 37-42.

Yassein, M. B., Khaoua, M. O., Mackenzie, L. M., Papanastasiou, S., \& Jamal, A. (2006). Improving route discovery in ondemand routing protocols using local topology information in MANETs. In Proceedings of the ACM international workshop on Performance monitoring, measurement, and evaluation of heterogeneous wireless and wired networks (pp. 95-99). ACM.

Zarei, M. (2009). Reverse AODV routing protocol extension using learning Automata in ad hoc networks. In 2nd International Conference on Computer, Control and Communication (IC4) (pp. 1-5). IEEE.

Zarei, M., Faez, K., \& Nya, J. M. (2008). Modified Reverse AODV routing algorithm using route stability in mobile ad hoc networks. In International Multitopic Conference (INMIC) (pp. 255-259). IEEE. 